\title{
The glass swing: a vector active structure made of glass struts and 3D-printed steel nodes
}

\author{
A. H. Snijder 1 - L. P. L. van der Linden • \\ C. Goulas - C. Louter $\mathbb{D}$ - R. Nijsse
}

Received: 7 April 2019 / Accepted: 18 October 2019 / Published online: 13 November 2019

(C) The Author(s) 2019

\begin{abstract}
The majority of glass used in load-bearing structures is as planar elements. Some projects exist that use linear glass elements. This paper discusses in broad terms the design, engineering, and fabrication of a unique vector active glass structure consisting of glass bundles and partly printed steel connections.
\end{abstract}

\footnotetext{
A. H. Snijder $(\varangle) \cdot$ C. Louter

Faculty of Architecture and the Built Environment, Delft University of Technology, Julianalaan 134, 2628 BL Delft, The Netherlands

e-mail: a.h.snijder@tudelft.nl

L. P. L. van der Linden

Arup, Amsterdam, The Netherlands

e-mail: lennert.van-der-linden@arup.com

L. P. L. van der Linden · R. Nijsse

Faculty of Civil Engineering and Geosciences, Delft

University of Technology, Delft, The Netherlands

C. Goulas

Faculty of Mechanical, Maritime and Materials

Engineering, Delft University of Technology, Delft,

The Netherlands

e-mail:k.goulas@tudelft.nl

URL: http://www.ramlab.com

C. Goulas

Rotterdam Fieldlab Additive Manufacturing BV

(RAMLAB), Scheepsbouwweg 8, 3089, JW Rotterdam,

The Netherlands

C. Louter

Institute of Building Construction, Technische Universität

Dresden, Dresden, Germany

e-mail: christian.louter@tu-dresden.de
}

A structure was conceived that utilizes the glass bundles in a way that can be directly experienced by the users: a swing. To create a non-standard form for the swing, a structural optimization procedure was used. To realize the structure, a novel steel node was developed and produced using an additive manufacturing technique in steel. These novel applications have made the project innovation heavy, particularly considering the limited timeframe for its development and construction. Description is given of the several optimization techniques incorporated in the digital process, the assembly and testing of the glass bundles, and the manufacturing of the steel nodes by Wire and Arc Additive Manufacturing.

Keywords Linear structural glass elements · Dry assembled glass bundle struts - Steel additively manufactured nodes

\section{Introduction}

The Glass Swing is the latest in a series of glass vector active structures of increasing complexity built at Delft University of Technology. The first structure was a linear (1D) application of a glass bundle as a column by (Oikonomopoulou et al. 2017) as shown in Fig. 2a. The follow up project was the application of the bundle in a planar (2D) truss structure shown in Fig. 2b, by (Snijder et al. 2018). Subsequently, a spatial truss (3D) was constructed spanning 6 meters, shown in Fig. 2c. 


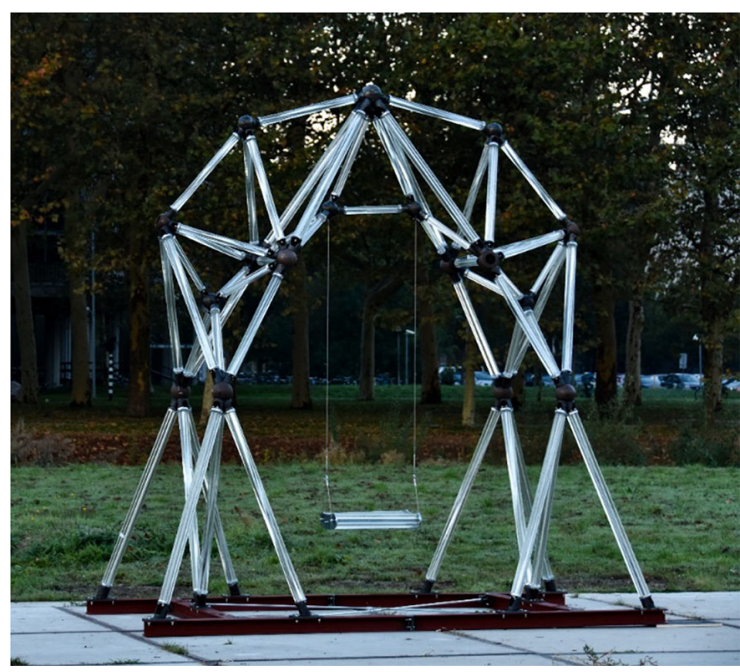

Fig. 1 The Glass Swing after completion at Delft University campus. Photo: José Galan

This project has not been published to date. The logical next step was to take the concept of the space truss one step further and improve the geometrical lay-out and chosen glass bundle cross sections by optimization techniques. Such an opportunity presented itself when the Glass and Transparency Research group at Delft University of Technology was invited to present its latest developments in structural glass research at the GlassTec trade fair 2018 in Düsseldorf. This paper describes the design, engineering, and manufacturing of the Glass Swing (see Figs. 1, 2d, 31).

\subsection{Concept}

The Glass Swing is an attempt to bridge the disparity between the fields of Glass Art and Architectural Glass. Little synergy exists between these two fields: Glass art is sculptural, curvaceous and spectacular. Architectural glass is predominantly plain, flat, and almost invisible. The design attempts to bring together the two fields to create architectural structures that possess the qualities of glass art; addressing form, light, playfulness, elegance and function. The Glass Swing aims to utilize the aesthetic potential of glass while at the same time creating a strong, safe, and functional object.

\subsection{Existing research and applications}

The concept for an axially loaded glass element as a bundle of glass rods, rather than compound glass tubes, was first put forward in a publication by Rob Nijsse (2003). The concept was 'safety in numbers: After breaking of one or two rods, the rest of the bundle can still transfer forces'.

The glass bundles are developed to be loaded axially as struts in spatial structures or as columns in more traditional orthogonal structures. The development of the glass bundle which has been applied in the truss structure for the swing is preceded by a number of earlier applications of axially loaded glass linear elements. An overview of research on glass columns is given in (Oikonomopoulou et al. 2017). Most existing glass columns are constructed from flat glass.

Glass struts in vector active structures have also found a number of applications in projects, so far primarily as glass tubes. A tensegrity structure of glass tubes and steel rods was presented in 1996 at GlassTec (Achenbach et al. 2002). A space frame structure consisting of Schott glass tubes and MERO nodes was presented in 2000 at Bauma Munich. A trussed beam with laminated glass tube struts was subsequently developed (Doenitz et al. 2003) and the glass tube strut found its first application in an architecture project in the Foster and Partners design of Tower Place, London. A similar concept, using a combination of glass and acrylic tubes, was developed in Delft by F. Bos and F. Veer (Bos et al. 2006).

\subsection{Digital workflow}

The design and manufacturing process of the Glass Swing was digital from start to finish. The design process was accomplished in a single model in the parametric environment of the visual scripting software Grasshopper3D embedded into Rhinoceros3D. With this parametric approach it was possible to explore form in the beginning and to make quick adjustments in the later stages. Moreover, the same approach was used to extract the required data for manufacturing of the glass bundles and the steel nodes.

To create a design with a strong focus on the structural function of the glass, the final form was generated using two structural optimization steps and one intermediate step based on designer's intuition. Subsequently, the nodes and their coherent detailing were designed based on available materials and manufacturing restrictions, while the final checks were carried out in Oasys GSA. The final step was the extraction of information to digitally manufacture the nodes and all 
(a)

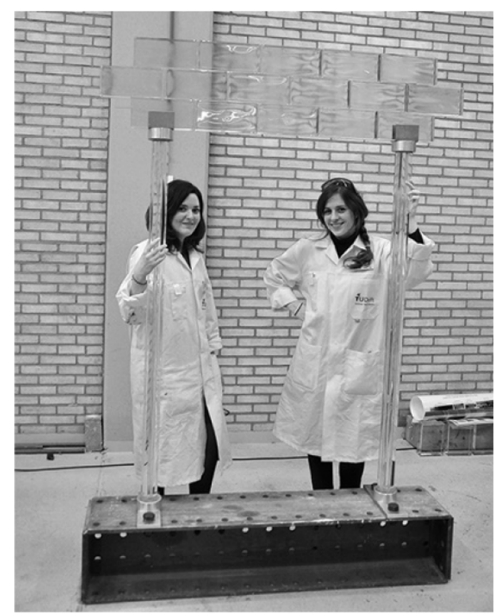

(c)

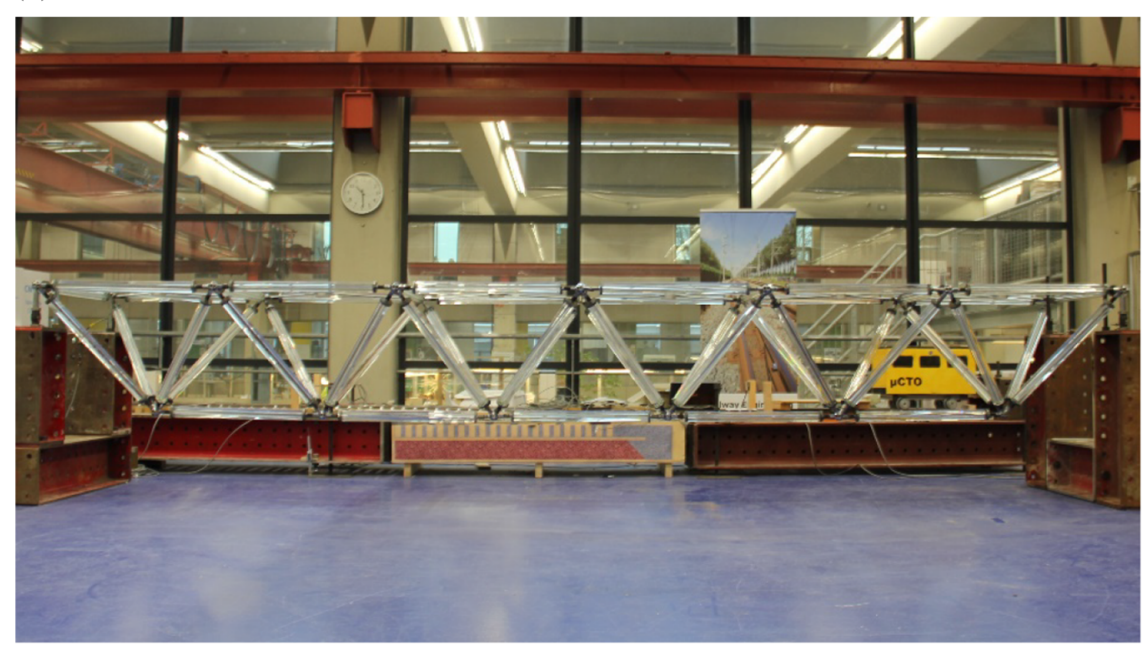

(b)

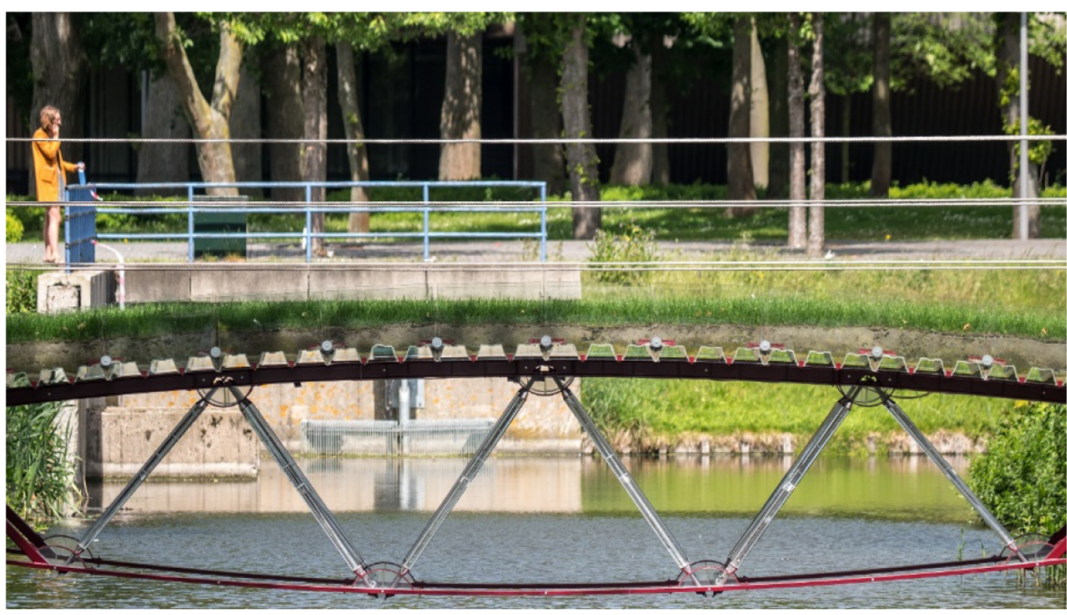

(d)

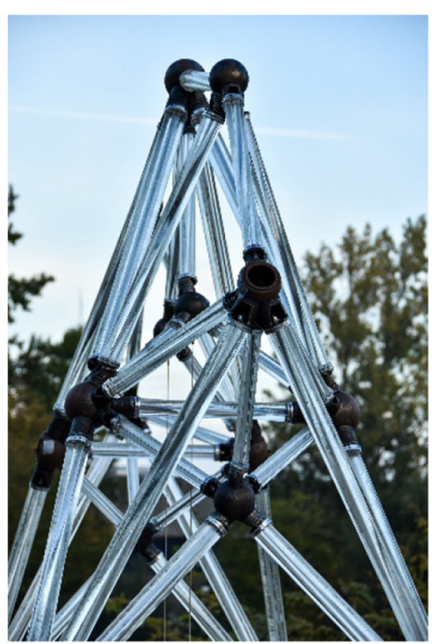

Fig. 2 The progression of projects with glass bundles at TU Delft. a Glass Column. Photo: Oikonomopoulou. b Glass Truss Bridge. Photo: Frank Graphdude Auperle. c Glass space truss beam. Photo: Christian Louter. d Glass Swing. Photo: José Galan

the parts for the glass rods. This workflow is illustrated in Fig. 3.

In short, the following steps were taken:

1. Optimization of material position using topology optimization software (see Sect. 2-Form generation) and interpretation of the result to a wireframe diagram using human engineering design intuition;

2. Optimization of the cross sections of the truss elements (see Sect. 3-The glass struts);

3. Design of the nodes (see Sect. 4-Additively manufactured steel nodes);

4. Detailed design (see Sect. 5-Structural analysis of the swing).

\section{Structural form finding}

The geometry of the truss structure is the result of topology optimization using Bidirectional Evolutionary Structural Optimization (BESO) (see Fig. 4). BESO is a method to study the topology of a structure based on the ESO method (Xie and Steven 1993) (Xie and Steven 1996). With this method an answer is found where to apply material and voids within a given domain with predefined boundary conditions, loads, and possibly additional design restrictions such as the location and size of prescribed holes or solid areas. 


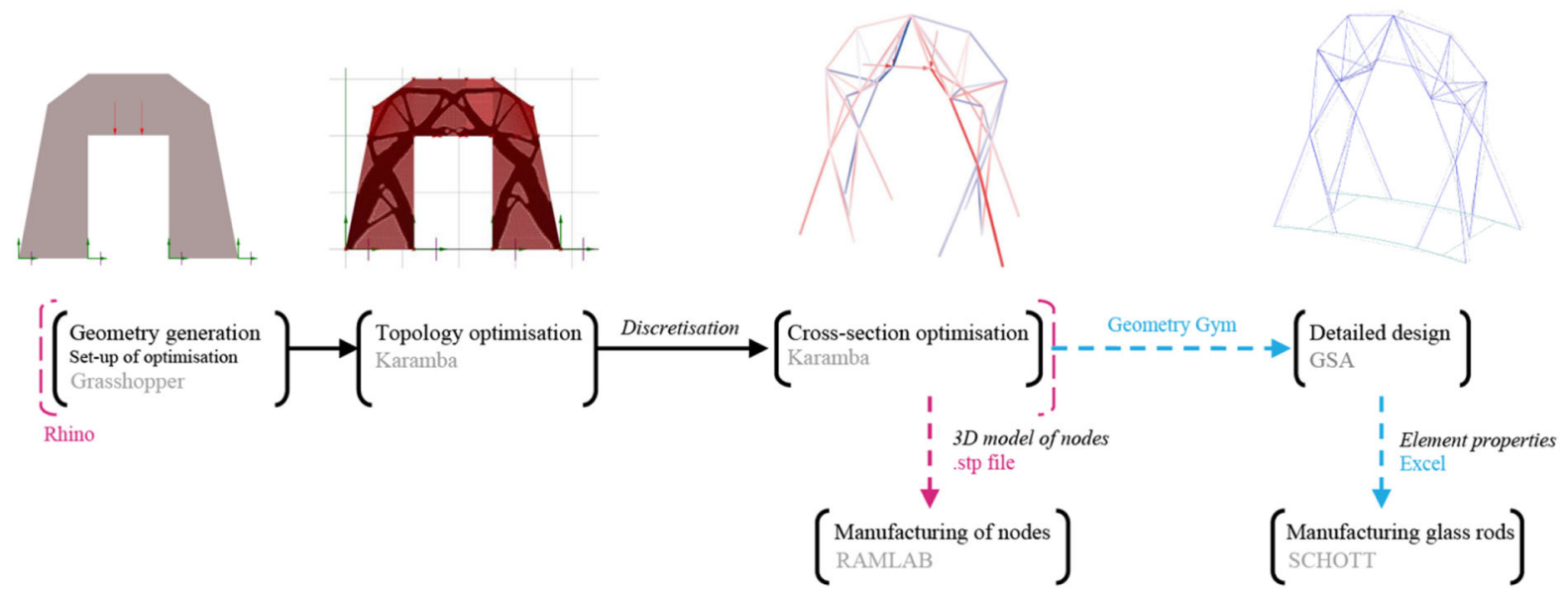

Fig. 3 Overview of the applied digital workflow for the design and manufacturing process of the Glass Swing

(a)

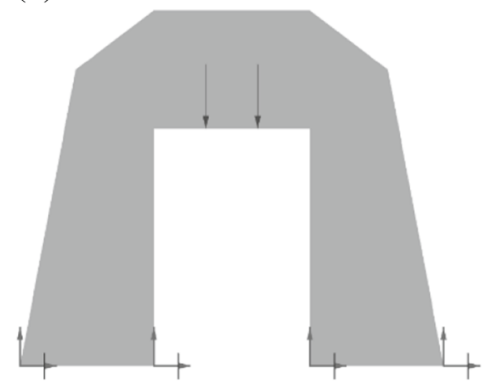

(b)

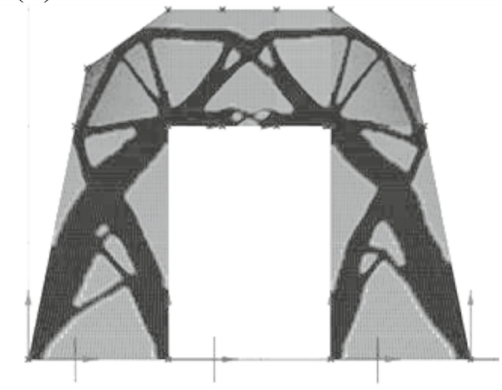

(c)

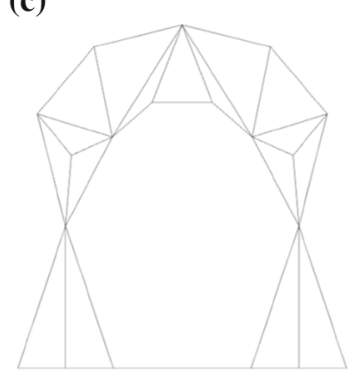

Fig. 4 a Initial material envelope and loads for BESO optimization. b Result of BESO optimization. In black the material that has not been removed in the process. $\mathbf{c}$ Discretization and ratio-

Bidirectional refers to allowing material to be removed and added simultaneously during the process.

The topology optimization was carried out with the software Karamba3D. The most important load case was used for the optimization: a swinging weight exerting a simultaneously working vertical and horizontal force. The final result depended highly on the initial chosen design domain in which the structure was developed. Since the design domain was parametrically defined it was possible to explore many variations before settling on both a structurally and aesthetically appealing design.

Topology optimization results tend to be organic structures. This was also the case for the optimized swing structure lay-out. The organic structure was interpreted and discretized to a structural wireframe model. In this process the designing engineers relied on their structural and aesthetic judgement to translate nalization of the result from the BESO procedure to a static truss structure

the result of the BESO process into a buildable structure.

\section{Development of the glass struts}

\subsection{Glass bundle: bonded assembly}

The bundle was developed as a column but the first application in a structure was as a strut in a two dimensional truss for a pedestrian bridge developed at TU Delft. Shown in Fig. 2b. In the bridge the bonded bundle configuration is applied (Fig. 5a). In the swing the dryassembled bundle configuration is applied (Fig. 5b). The decision to use the dry-assembled bundle was made on the basis of the following experiences:

The glass extrusions are not perfectly straight and this leads to uneven contact surfaces between the star profile and the surrounding rods. With the applied adhe- 
(a)

$$
\text { 3. 2. } 1 .
$$

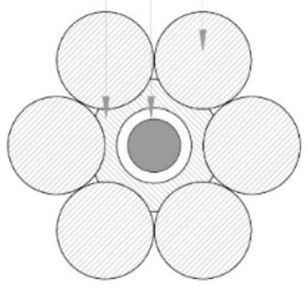

Fig. 5 a Cross section of bonded glass bundle. 1. Duran Glass rod (Schott). 2. Steel pre stressing rod S235, chrome coated. 3. Central star shaped glass profile Duran (Schott) adhesively bonded to the surrounding glass rods using a UV hardening adhe- (b) 2. 1.

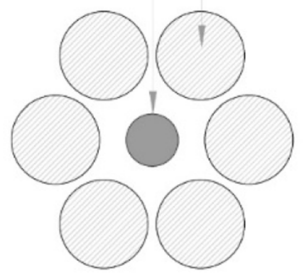

sive. b Cross section of dry assembled glass bundle. 1. Duran Glass rod (Schott). 2. Steel pre stressing rod S235, chrome coated
Fig. 6 Principle detail of the dry assembled glass bundle strut as used in the Glass Swing. In the swing MDF (medium density fibreboard) has been used. Other interlayers have also been tested (see Sect. 3.3.1)

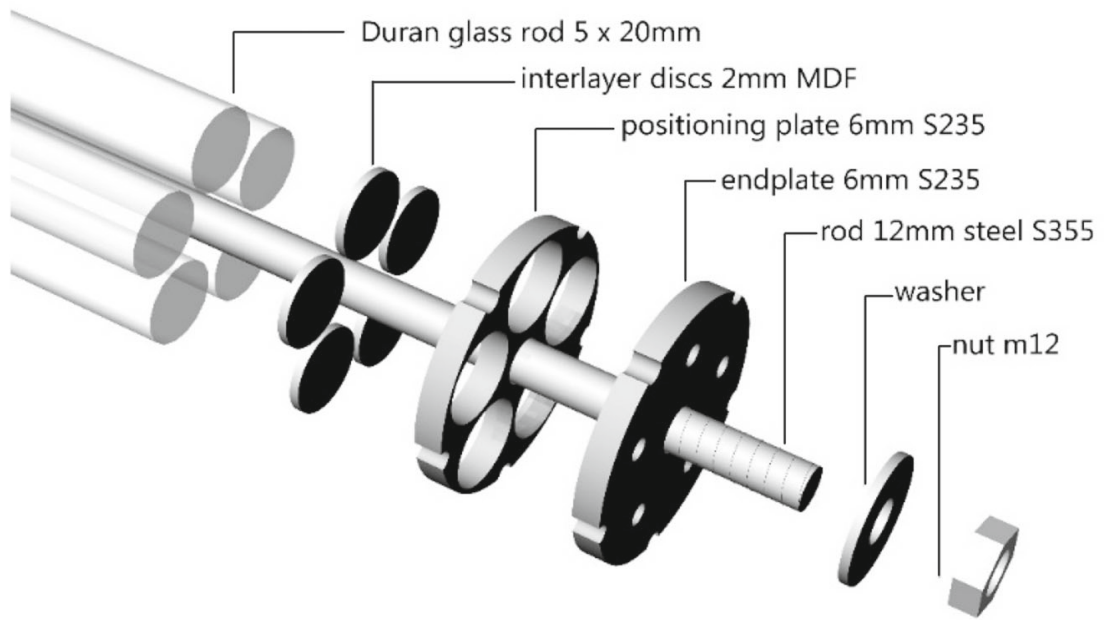

sive (Delo UV hardening) these conditions are unfavorable and in some cases means the surfaces are not properly bonded. For the calculation of the second moment of area one can therefore not assume a combined crosssection. Rather, in the worst case scenario, the extrusions are hardly bonded and the second moment of area should be calculated as the sum of the second moments of area of the individual extrusions. This negates the positive effect of the bonding on the bearing capacity of the bundle. The air spots between the bonded surfaces also have a big visual impact beside the negative impact on the structural behavior.

To bond the bundle a special star shaped central profile is needed, to which the outer rods can be glued. This profile is only available in one specific diameter (Conturax 2017). So to have a more optimal match between the loadbearing capacity of the bundle and the expected load on the bundle the dry assembly method is chosen. This allows for a wide range of rod diame- ters and also in the number of rods used in the bundle. Further reading on the bonded bundle concept can be found in (Oikonomopoulou et al. 2017) and (Snijder et al. 2018). The assembly of the dry assembled bundle used in the swing is shown in Fig. 6.

\subsection{Glass bundle: dry assembly}

To allow the strut to take both compressive and tensile forces the bundle is pre-stressed using a central steel rod. The glass rods are loaded in compression, the central steel rod takes the tensile forces. The pre-stress is introduced in the bundle by applying a moment to a nut on the threaded end of the steel rod. The nut presses against a steel end cap that transfers the compressive force in the glass.

A problem with this method of applying the prestress is that it can result in rotational deformation of the bundle. The bundle itself, consisting of individual 

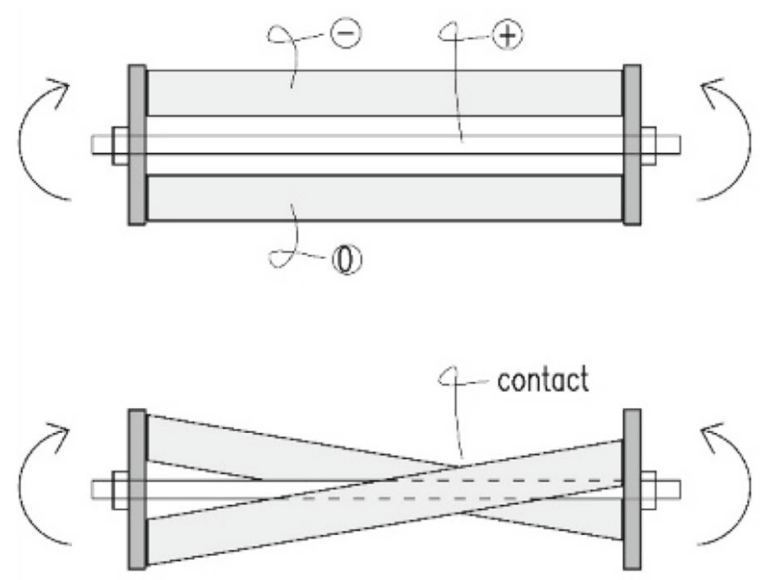

Fig. 7 Bending in a twisted dry assembled bundle. When the bundle is twisted until the individual rods are in contact in the middle, the rods themselves are subjected to bending instead of

rods joined only at their ends, is unable to resist torsion. While rotating the nut when applying the pre-stress the endcaps are securely clamped to prevent their rotation (see also Fig. 19). This does not prevent some elastic torsional deformation to occur in the steel pre-stressing rod. When the endcaps are released, the pre-stressing rod springs back to its original state, thereby sometimes twisting the bundle. Further research is needed to devise a better method. The current pre-stressing method is described in more detail in Sect. 3.5.

A twisted bundle is structurally compromised. When the bundle is straight, it can resist bending by means of the internal moment created by compression in the glass and tension in the steel rod. When the bundle is twisted until a contact point occurs between the individual bars, the bundle's capacity for bending is found to be greatly reduced (see Fig. 7). When subjected to an external moment, the three contact points (at the ends and at the contact point in the middle created by the twist) are loading the glass rod in three point bending. Such bending of the rods causes high tensile stresses on the surface which has led to failure of individual rods. The failure occurred during the pre-stressing phase and these twisted bundles were discarded.

\subsection{Exploratory experiments}

During the development of the dry-assembled bundles a number of prototypes were made and tested. Three
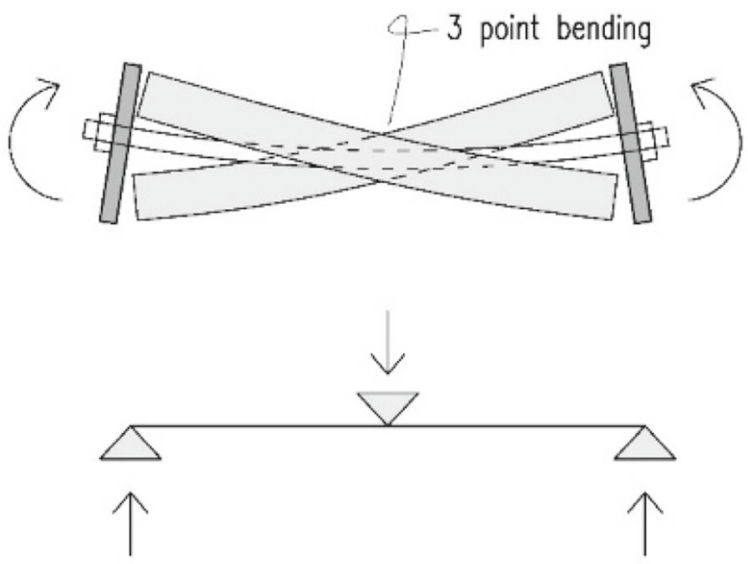

normal force. Tension is indicated wth '+', compression with '-' and zero force with ' 0 '

aspects of the dry-assembled bundle were addressed in particular by the prototypes:

a. Means of transferring loads into glass (i.e. choice of interlayer) (Sect. 3.3.1);

b. Use of lateral coupling plates in middle of bundle to increase critical buckling load (Sect. 3.3.2);

c. Method of applying and measuring pre-stress in the bundle (Sect. 3.5).

\subsubsection{Load introduction to glass}

In case of the adhesively bonded bundle struts, the first design was to use lead between the glass and the end cap to ensure an even load distribution in the glass rods (Fig. 8). This concept was tested in 2016 in the Stevin lab of the TU Delft when preparing and testing prototypes for the Glass Truss Bridge (experiments not published). It was observed that the lead interlayer underwent considerable relaxation. So much that, in time under constant pressure, the lead is squeezed out from between the glass and the end cap altogether. Oikonomopoulou uses a steel end cup, rather than a cap to restrain the lead interlayer laterally (see Fig. 8). In cases where there was space in between the rods, the lead would squeeze between the rods and pry them apart, leading to reduction of bearing capacity over time. It was concluded a stiffer material exhibiting less relaxation could lead to better and time-independent performance. For this reason soft 


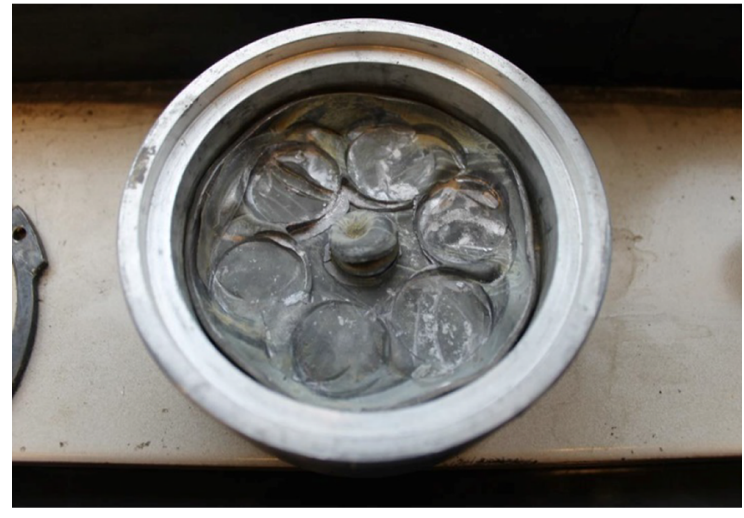

Fig. 8 Load introduction pre-study: lead interlayer in an end cap, photographed after loading and disassembling adhesively bonded glass bundle

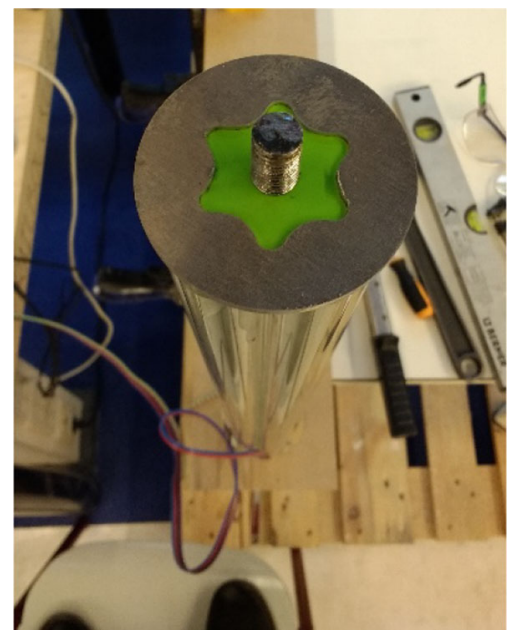

Fig. 9 Load introduction pre-study: bonded glass bundle with an aluminum interlayer as previously investigated by (Snijder et al, 2016)

aluminum was selected for the bonded bundles of the bridge project (see Fig. 9).

In the case of a dry-assembled bundle the end cap introduces axial load in the glass bundle and also keeps the bundle together, constraining lateral movement of the rod ends. Individual rods are prevented from slipping off the endcap by setting them in recesses in the steel plate. The interlayer that transfers the compressive force from the steel endcap to the glass is placed inside the recesses (see also images 6, 10 and 11). The interlayer should not have a hardness greater than glass to avoid peak stresses and should exhibit little or no time dependent deformation (Bos et al. 2006). Two materi-

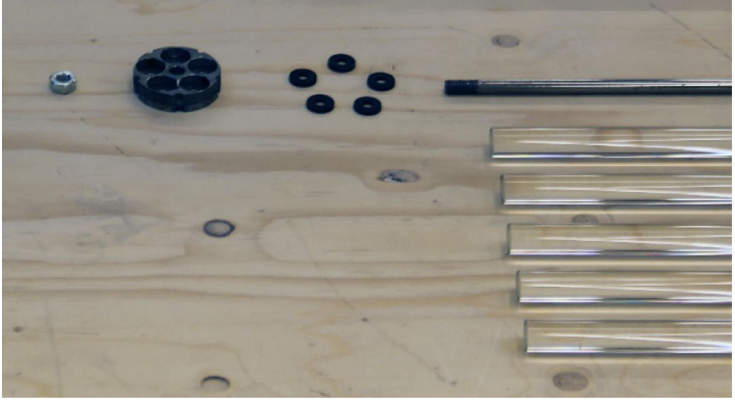

Fig. 10 Load introduction pre-study: individual components for the dry assembled bundle with rubber ring interlayer

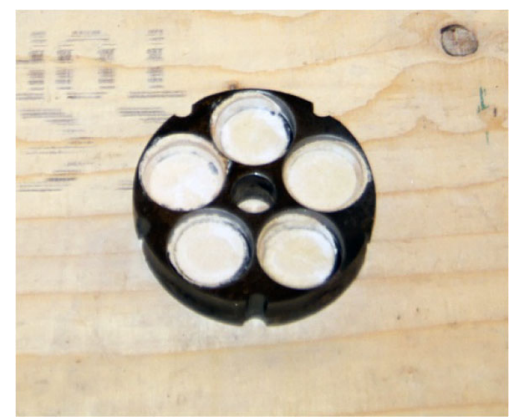

Fig. 11 Load introduction pre-study: endcap with Hilti-HIT after loading and disassembly

als were tested in prototypes: rubber rings (Fig. 10) and injection with Hilti-HIT-CR 500 mortar (Fig. 11). As shown in Fig. 6, the interlayer used in the bundles in the final swing is MDF. This is not a weather resistant material and not suitable for outdoor use. POM (polyoxymethylene) could be a more durable alternative.

\subsubsection{Lateral coupling for higher buckling load.}

The second moment of area of the dry-assembled bundle is almost a factor 10 lower than the bonded bundle, if properly glued. To mitigate this loss of load-bearing capacity the effect of an extra lateral coupling of the rods halfway their length is investigated. The coupling is achieved by a transparent laser cut PMMA (polymethyl methacrylate) disc that holds the rods and the steel pre-stress tendon in place. The disc is depicted in Fig. 12 and its placement in the bundle in Fig. 13. PMMA was chosen because it is transparent and easily laser cut. The hypothesis is that this prevents the buckling of individual rods; the whole bundle would have to buckle as one (Fig. 14). 
Fig. 12 The PMMA coupler disc
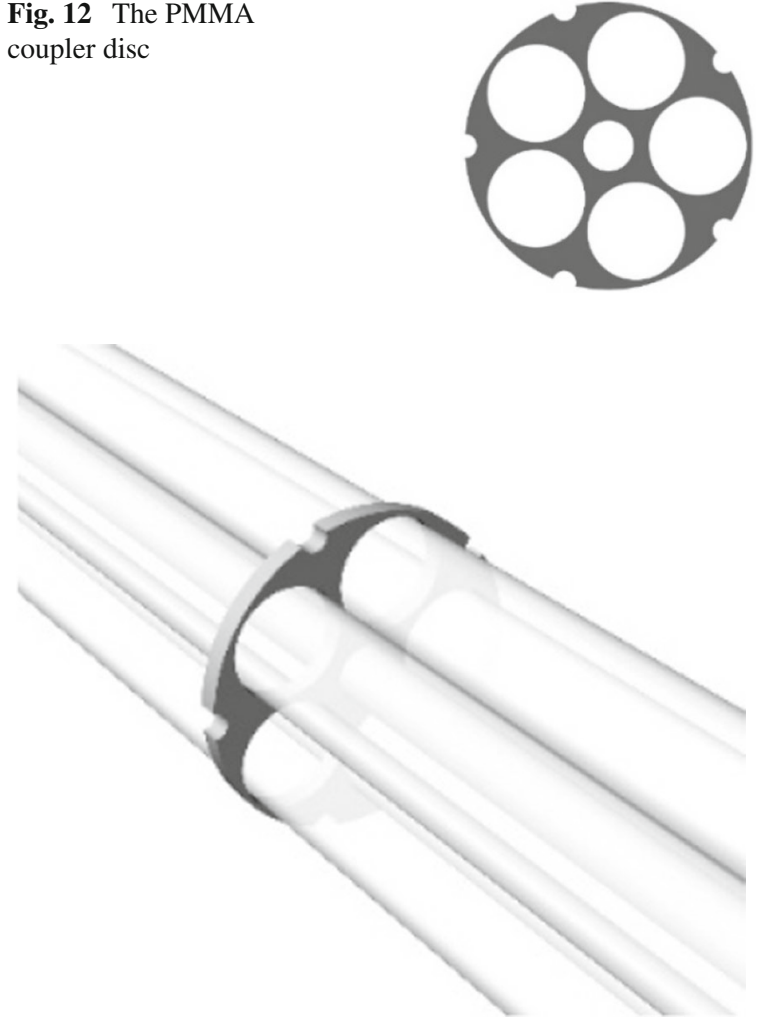

Fig. 13 The coupler disc on the bundle

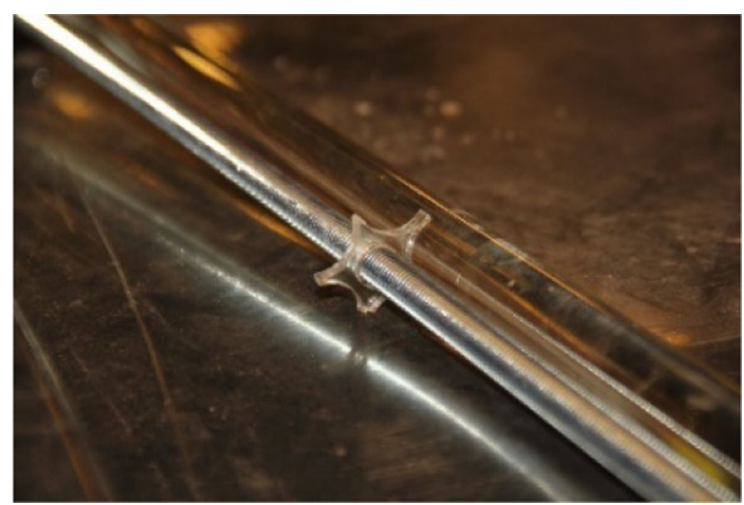

Fig. 14 Pre-stressing rod with remains of coupler after loading

\subsubsection{Test setup}

The three prototypes were tested in a compression machine. The setup of the test is shown in the diagram in Fig. 15a and the photo in 15b. Figure 16a, b show how the hinged boundary conditions have been realized. The small number of specimens (1 per prototype) for these exploratory experiments means that these results are not conclusive, and only give a rough indication of the structural behavior of the bundles.

\subsubsection{Results}

Table 2 shows the results of the compression test on the three prototypes.

\subsubsection{Discussion}

The recorded loads at failure, shown in table 1, seem to indicate that the choice between injectable mortar or rubber interlayers has limited effect on the load-bearing capacity of the bundle. A bigger series of experiments on an expanded range of interlayer materials is recommended to determine the impact of the choice of interlayer.

The lateral coupling by the PMMA perforated disc did not lead to a significant change in load-bearing capacity. The coupler failed before a significant extra load was resisted by the bundle. The coupler failed as shown in Fig. 14. Additional experiments and FEM models are required to determine if such a coupler, if strong enough, could significantly increase the loadbearing capacity of the bundle.

The theoretical critical buckling force given in Table 1 is calculated using Euler's buckling formula. It is assumed that the second moment of area of the rods can be summed and that the ends of the rods are supported by perfect hinges. The results in Table 2 from the tests on the three prototypes show that the lower bound theoretical buckling load of $35 \mathrm{kN}$ is significantly lower than the experimentally found loads.

Two considerations given below can provide a more nuanced method for calculating the critical buckling load for the tested bundles:

(1) For the experiment the glass rods were cut and polished manually by students, this led to deviation of the lengths of the individual rods being significant; up to $\pm 1 \mathrm{~mm}$. This means that the total force on the steel end cap is primarily transferred to three of the five rods in the bundle. The three longest rods form the three contact points necessary to make equilibrium. The most unfavourable, but realistic scenario, is that the configuration of the glass rods in the bundle is such that two rods take half of the total load on one side of the endcap, and a single rod is loaded with the other half of the external load 
Fig. 15 a Schematization of the test setup. $\mathbf{b}$ Impression of test setup

Fig. 16 a Photo of ball hinge. b Photo of aluminum cylinder to receive glass bundle (a)

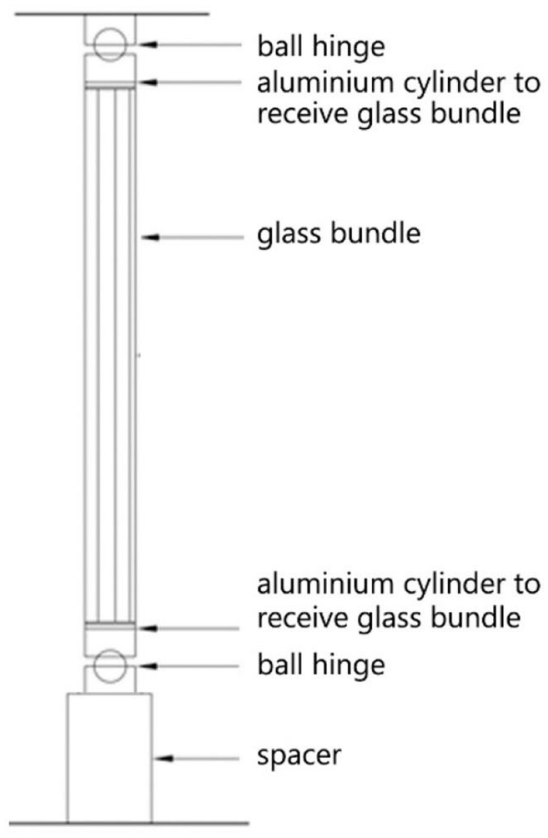

(a)

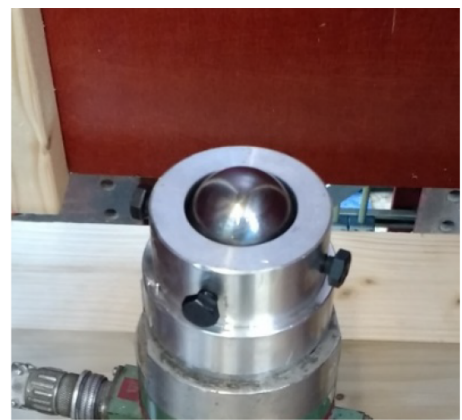

(b)

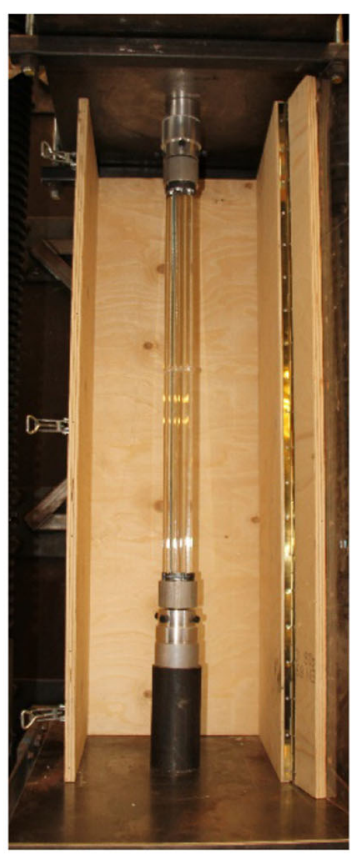

(b)

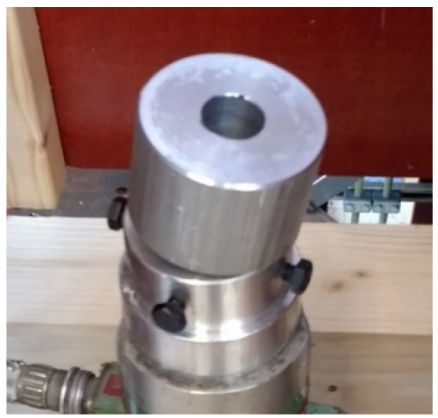

Table 1 Properties of tested glass bundles

\begin{tabular}{lll}
\hline & One rod & Bundle of 5 \\
\hline Euler's buckling force $[\mathrm{kN}]$ for fully hinged supports & 7 & $5 * 7=35$ \\
Buckling length: $[\mathrm{mm}]$ & 830 (endcap to endcap) & 880 (ball hinge to ball hinge) \\
Young's modulus glass $\left[\mathrm{N} / \mathrm{mm}^{2}\right]$ & 69000 & 39270 \\
Second moment of area $\left[\mathrm{mm}^{4}\right]$ & 7854 & \\
\hline
\end{tabular}

Table 2 Results of compression test on the three prototypes

\begin{tabular}{lll}
\hline Interlayer material & $\begin{array}{l}\text { Additional coupling } \\
\text { in the middle }\end{array}$ & $\begin{array}{l}\text { Compression force at } \\
\text { failure }[\mathrm{kN}]\end{array}$ \\
\hline Rubber ring & No coupling & 60 \\
Rubber ring & With coupling & 55 \\
Hilti & No coupling & 60
\end{tabular}




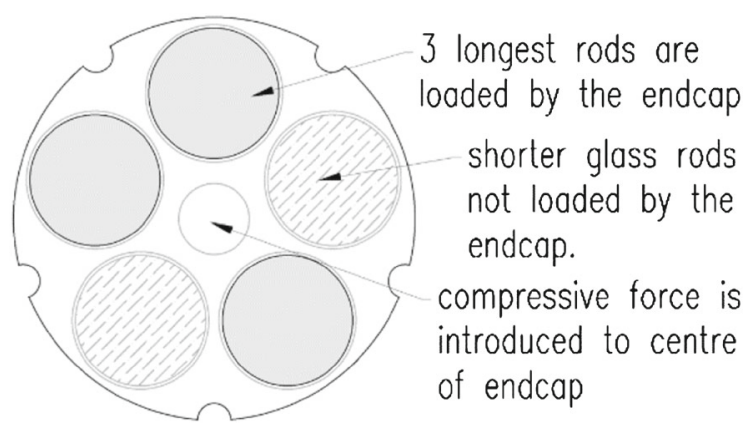

Fig. 17 Endcap with possible configuration of loaded and unloaded rods

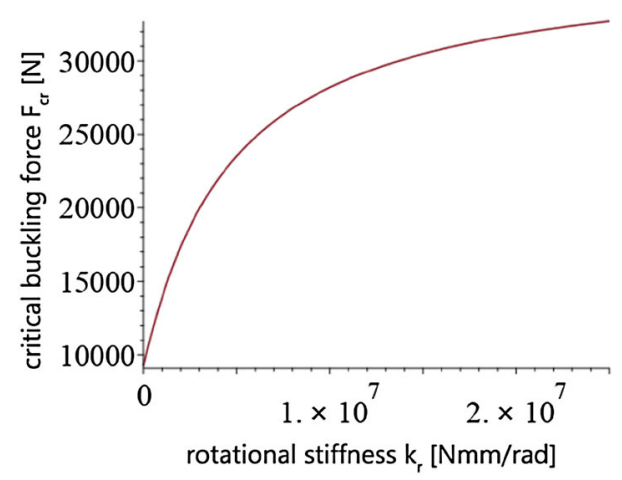

Fig. 18 Critical buckling force of a rod as a function of the rotational stiffness of the supports

(see Fig. 17). This suggests that the load-bearing capacity of the whole bundle is two times the critical buckling force of an individual rod. Further research is required to verify this assumption.

(2) The support conditions of the bundle itself can be considered near perfect hinges in the experiment setup. The glass rods are loosely fitted in the recesses in the steel endcap, and sit with the flat surface on the interlayer. The rotational stiffness of this support condition is unknown. The graph in Fig. 18 shows the critical buckling force of a rod as a function of the rotational stiffness of the supports, according to Eq. (1) (Hartsuijker and Welleman 2007). A rotational spring stiffness in the range $10<\mathrm{k}_{\mathrm{r}}<20 \mathrm{kNm} / \mathrm{rad}$ gives a buckling force of between 25 and $30 \mathrm{kN}$ for a single rod or 50 to $60 \mathrm{kN}$ per bundle, when assuming the scenario described in the previous paragraph.

$$
\begin{aligned}
F_{c r} & =\frac{(5+2 \rho)^{2}}{(5+\rho)^{2}} \cdot \frac{\pi^{2} E I}{l^{2}} \\
\rho & =\frac{k_{r} \cdot l}{E I}
\end{aligned}
$$

\subsection{Applying pre-stress to the bundles}

Different means of pre-stressing the bundles, and the method for measuring the pre-stress were explored. For the bonded bundles of the bridge the pre-stress in the glass was measured using three strain gauges on the glass rods (results not published). For the dryassembled bundles a less direct but more efficient method using a force gauge was used, see Fig. 19. Some exploratory measurements were taken to get an indication of the reduction of pre-stress in the bundles due to relaxation of the interlayer. These measurements were indicative only and not fit for publication. The method of pre-stressing by turning a nut, as depicted in Fig. 19, was finally the most efficient. The only drawback of the method is that the central steel rod will in some cases undergo elastic deformation around its central axis (torsion). As a result, when the clamps are removed the bundle can twists as the steel rod returns to its initial position.

(a)

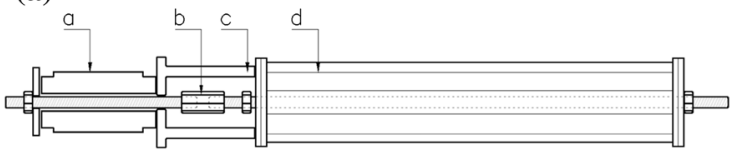

(b)

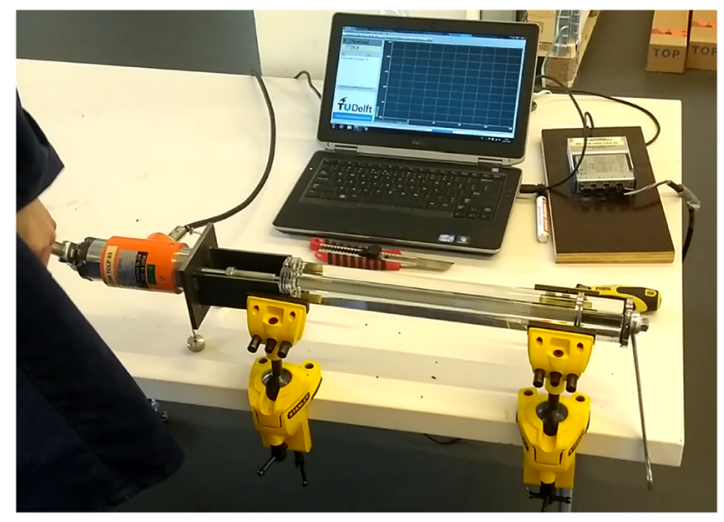

Fig. 19 Setup for pre-stressing of the glass bundles. a Diagram with a: force gauge, b: extension nut, c: steel bracket, and $d$. bundle. b Photo of the pre-stressing setup 
Fig. 20 Projected vertical force for a swing motion with a mass of $150 \mathrm{~kg}$ $(1.5 \mathrm{kN})$ with a swing length of $2 \mathrm{~m}$

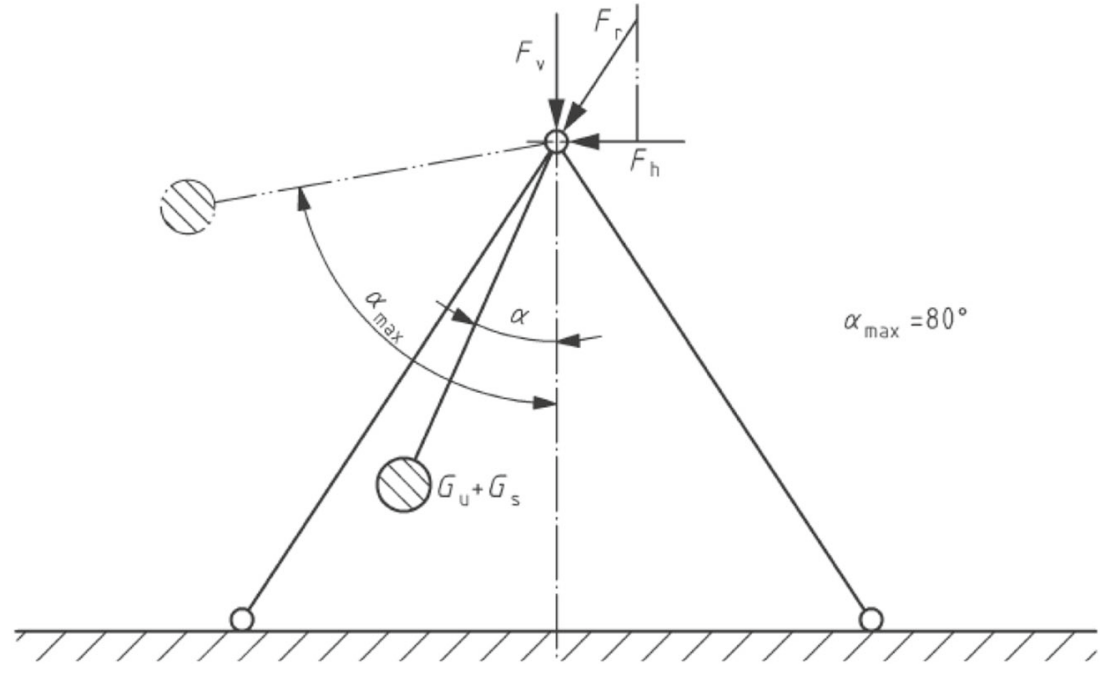

\subsection{Cross section optimization}

The wireframe model, discussed in Sect. 2 and shown in Fig. 3c, was used to assign the cross-sectional dimensions to the struts. This was done by size optimization, a form of structural optimization that defines ideal crosssectional dimensions based on the expected forces. The normative design criteria for the struts was buckling since the struts consist of slender rods that are prone to geometrical instability. The stiffness of the struts was conservatively determined as the sum of the individual buckling loads of the rods. This is proven by the test results given in Sect. 3.4. A safety factor of 2 was applied on the loads which was found to be a safe factor to compensate for imperfection of the rods and unforeseen loading due to e.g. mistakes in the construction of the structure as the structure is expected to be assembled and disassembled numerous times. With the formula for Eulerian buckling the required radius of the glass rods was determined:

$F_{k}=\frac{\pi^{2} E I_{y}}{l_{k}^{2}}$

With,

$$
\begin{aligned}
I_{y} & =\frac{5 \pi r^{4}}{4} \\
l_{k} & =l \\
F_{k} & =2 F
\end{aligned}
$$

Yields,

$r=\left(\frac{8 F l^{2}}{5 \pi^{3} E}\right)^{1 / 4}$

During the motion of the swing, the force vector is varying from 0 to 90 degrees resulting in unique forces in the struts per load angle. Theoretically, all angles should be incorporated while assigning the cross-sections. However, this would have led to a significant increase in computational time. In order to simplify the crosssectional design, one load vector at a specific angle was used with the highest resulting forces in the structure.

To find this critical angle, the evolutionary solver Galapagos-imbedded in the software Rhinoceros / Grasshopper-was used. With the forces as variable in the objective function, the fitness was maximized to find the critical angle of approximately 15 degrees to the vertical. The applied mass on the swing was determined by NEN-EN 1176-1 (Table A.1), adding the mass of the users $G_{u}(120 \mathrm{~kg})$ with the mass of the swing seat $(20 \mathrm{~kg})$ and cables $\mathrm{G}_{\mathrm{s}}$ :

$G=G_{u}+G_{s}$

The load expressed in $F_{h}, F_{v}$, and $F_{r}$ (indicated in Fig. 20) was determined by application of the load factors $\mathrm{C}_{\mathrm{h}}, \mathrm{C}_{\mathrm{v}}$, and $\mathrm{C}_{\mathrm{r}}$ as per NEN-EN 1176-1 B.4. $\mathrm{F}_{\mathrm{h}}, \mathrm{F}_{\mathrm{v}}$, and $\mathrm{F}_{\mathrm{r}}$, are determined by:

$$
\begin{aligned}
& F_{h}=C_{h} \cdot g \cdot\left(G_{u}+G_{s}\right) \\
& F_{v}=C_{v} \cdot g \cdot\left(G_{u}+G_{s}\right) \\
& F_{r}=C_{r} \cdot g \cdot\left(G_{u}+G_{s}\right)
\end{aligned}
$$


(a)
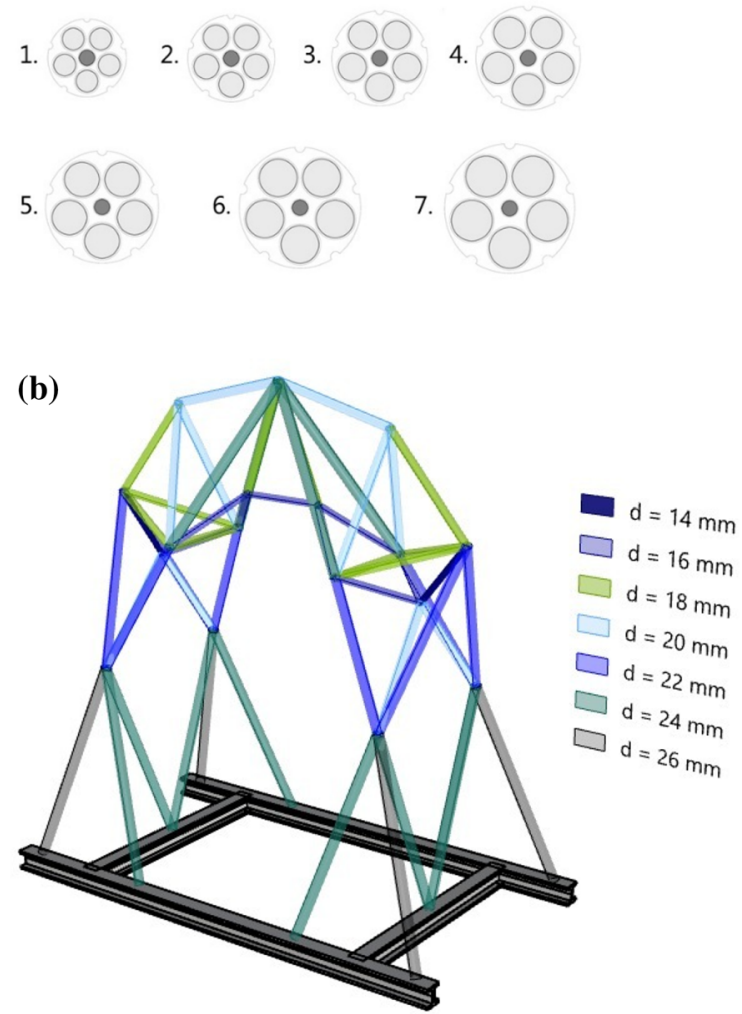

Fig. 21 a The seven different bundle strut cross sections utilized in the design of the swing. Glass diameters range from 14 to $26 \mathrm{~mm}$. b Position of the different cross sections in the structure

The cross-section optimization resulted in seven different cross-sections. The smallest bundles consisted of rods of $14 \mathrm{~mm}$ diameter, while the heaviest bundles were assigned to have $\mathrm{d}=26 \mathrm{~mm}$. Other bundles were assembled of rods with either diameters 16, 18, 20, 22, or $24 \mathrm{~mm}$. The variations in the cross-sections of the bundles are indicatively depicted in Fig. 21.

\section{Development of the additively manufactured steel nodes}

\subsection{Existing work}

In the past decade several research projects have been conducted on the application of Additive Manufacturing (AM) techniques to produce metallic structural elements for the building industry. Projects have been initiated to demonstrate the potential of these digital manufacturing techniques. Examples are the explo- ration for a novel design strategy to design and develop lightweight nodes for tensegrity structures by the redevelopment of an initial design by Arup, see Fig. 22 (Galjaard et al. 2015). The Innovative Joints for Gridshells study also demonstrates the potential of AM (Van der Linden 2015) together with the SmartNodes Pavillion (Seifi et al. 2016). For this project, nodes for spatial structures were digitally designed and produced to simplify construction issues. These research projects contain similarities. It concerned light-weight structures, uniqueness of the elements, and difficulties of production that could be overcome by the application of AM. For all these projects the AM technique Direct Metal Laser Sintering (DMLS) was applied (Crolla et al. 2017).

With DMLS it is possible to very accurately produce elements with high strength metallic material. However, DMLS has some significant drawbacks when applied for the production of elements for the building industry. DMLS is a powder-bed process which is characterized by low deposition rates-the speed to build objects-which makes it costly to produce large volumetric objects. In order to anticipate this challenge, several research and commercial projects apply the technique Wire and Arc Additive Manufacturing (WAAM) to more competitively build large volume objects.

WAAM is a process that uses electric arc heat source and wire as feedstock to create a three dimensional object. It offers build rates two orders of magnitude or more higher than powder bed sintering processes. An example project in the building industry is launched by MX3D and Arup: the MX3D bridge. It demonstrates that it is possible to create a large three dimensional object—a bridge — by using WAAM (Mx3D. 2018). For the maritime industry, RAMLAB has produced the first additively manufactured produced ship propeller, see Fig. 23. This propeller has also already been Class approved (WAAMpeller 2018).

Next to these practical examples, the AiM2XL programme led by prof. Dr. I. M. Richardson is launched in June 2018 (Aim2XL 2018). TU Delft together with the Materials Innovation Institute (M2i) and RAMLAB initiated an ambitious, fundamental research programme aiming to remove the barriers limiting the full exploitation of the wire based additive manufacturing to deliver large metal parts.

Traditionally, part construction is approached from a processing perspective. In the AiM2XL program, a material centric approach is followed, in which design 


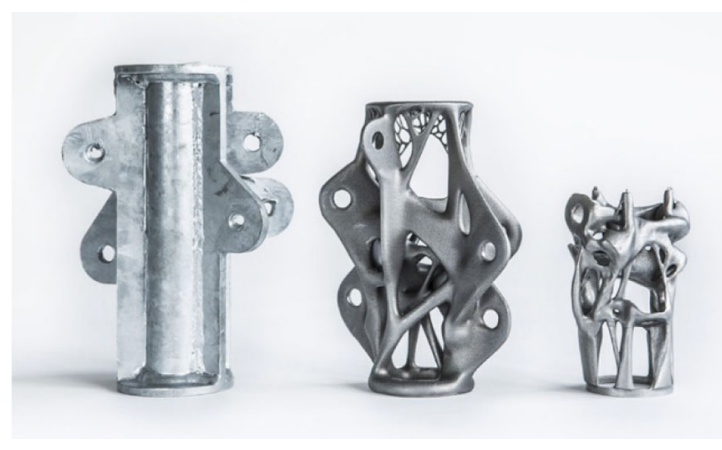

Fig. 22 Designs of the traditional tensegrity node (left), topology optimized (middle), second generation optimization (right) CArup

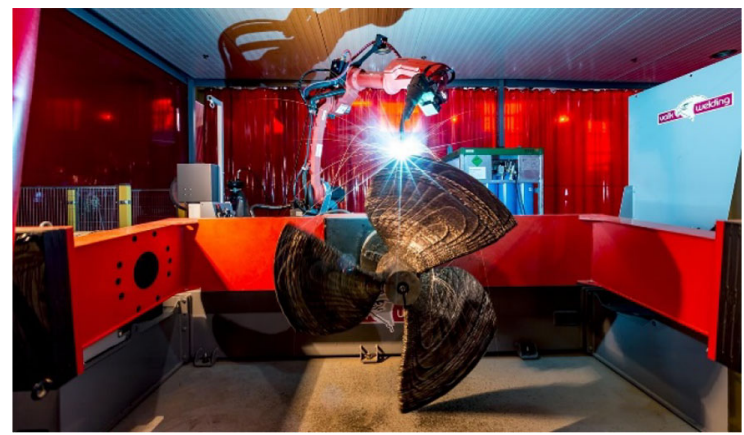

Fig. 23 The WAAMpeller, the first Class certified ship propeller by RAMLAB, courtesy RAMLAB

for properties plays a key role. Such an approach is not unique to large-scale structures, but is crucial at the large scale due to the relatively high heat inputs involved and the influence of macro-scale property gradients inherent in the deposited materials. A materials focus requires a sound understanding of the link between the thermal cycle and mechanical loading history of a component, which in turn determines the microstructure and resultant metallurgical, electrical and mechanical properties.

\subsection{Choice for additive manufacturing over traditional process}

The initial choice for additively manufacture the nodes was made due to the geometrical complexity of the nodes. The top node for example (Fig. 24) connects eight struts at small angles, in some cases less than twenty degrees. AM avoids a difficult traditional process of cutting and welding plates and tubes together.

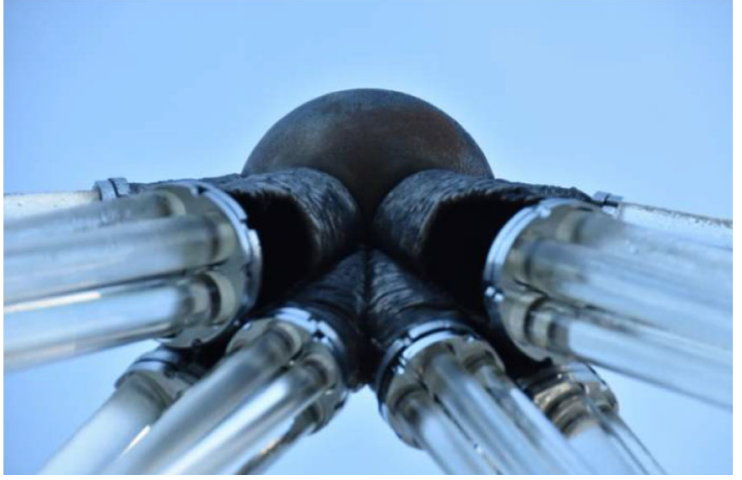

Fig. 24 Impression of the most complex node

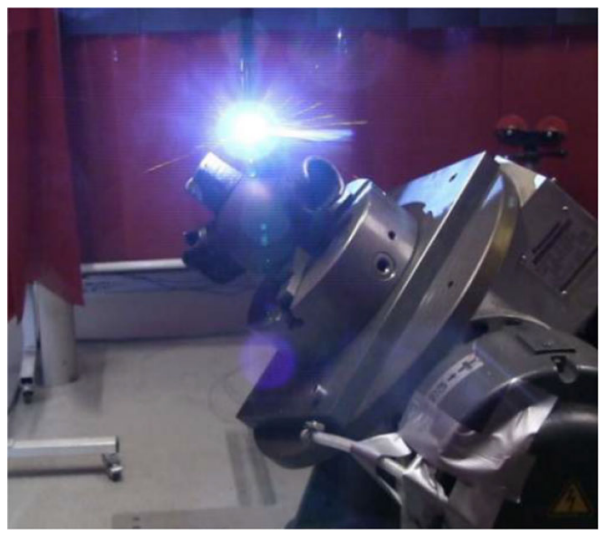

Fig. 25 Production of a node at the rotary table
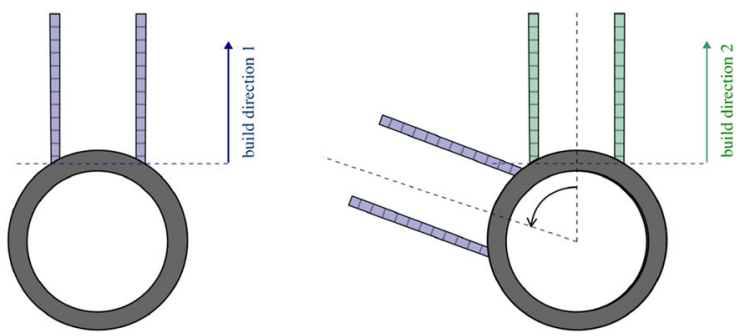

Fig. 26 Left: first printed tube to the cast sphere. Right: rotated sphere with second printed tube added to the node

Many parts would had to be assembled at the exact right angles and for most of the nodes under unique angles.

\subsection{Production strategy}

During design meetings with RAMLAB, it was decided to follow a partial 3D printing approach. This involved the use of a substrate that would form the base of the 
Fig. 27 Clashing walls of tubes required separate deposition strategies

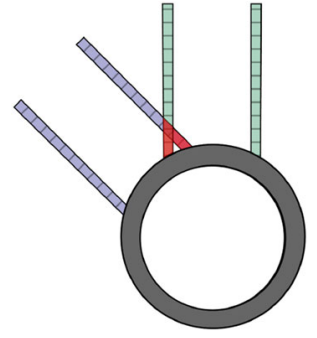

structural node, but also the starting point of the printing process. The choice was made to use a conventional cast spaceframe node on which tubes were to be printed to connect the glass struts. By placing the spheres on a rotary table with 6,5D axis freedom (Fig. 25) the sphere could be rotated in to the right angle to build the tubes perpendicularly to the substrate for all node geometries, see Fig. 26. Separate deposition strategies were applied in case of clashes of the wall of tubes, see Fig. 27. In those cases one single wall was printed that would eventually split in separate connecting tubes. Advanced monitoring and control systems developed at RAMLAB were used to ensure the quality of the printing process and the final geometry.

To allow for quick assembly of the swing structure, it was anticipated to use hollow spheres to reduce the weight of the nodes. However, wall thicknesses smaller than the weld bead size led to penetration through the wall. Working with an existing hollow cast spherical spaceframe node with wall thickness of $12 \mathrm{~mm}$ was found to be the most practical solution. The heaviest nodes were $10 \mathrm{~kg}$ per node with approximately $5 \mathrm{~kg}$ of added weight. This is within the legal weight to be lifted by one person during assembly.
The lightest nodes were $5 \mathrm{~kg}$ with approximately $2 \mathrm{~kg}$ of added material. Although the required printed material varies, the production time of the nodes was almost equal due to the longer cooling time for the smaller nodes (between 3 and 4h). RAMLAB used AM-Supramig HD $1.0 \mathrm{~mm}$ wire, provided by Lincoln Electric Europe in earlier projects with satisfying results and it was proposed to use this material for the nodes as well. Due to the limited dimensions of the printed parts, the residual stresses were not considered significant, implying that heat treatment was not necessary.

\subsection{Detailing of the connection}

The nodes consist of a cast hollow steel sphere with a wall thickness of $12 \mathrm{~mm}$. Two diameters for the nodes were used $(110 \mathrm{~mm}$ and $150 \mathrm{~mm})$, based on the amount of struts that connect to it and the angle between the struts. The smaller the angle between the struts, the larger the sphere and longer the added tubes had to be. On the steel sphere the connecting tubes were added up to an appropriate length to have sufficient space for mounting the glass bundles. A cut-away in the wall of the printed tube was a practical way to allow for access for the bolt connection. The glass bundles were mounted to the end plate that was manually welded to the tube. At the time of designing it was not possible to include the connector plate in the printed part. The principle of the detailing is given in Fig. 28.

A setback in the ease of construction has been a lack of accuracy in the connection between the connector plate to the node. This was compounded by the absence
Fig. 28 Detailing of the node

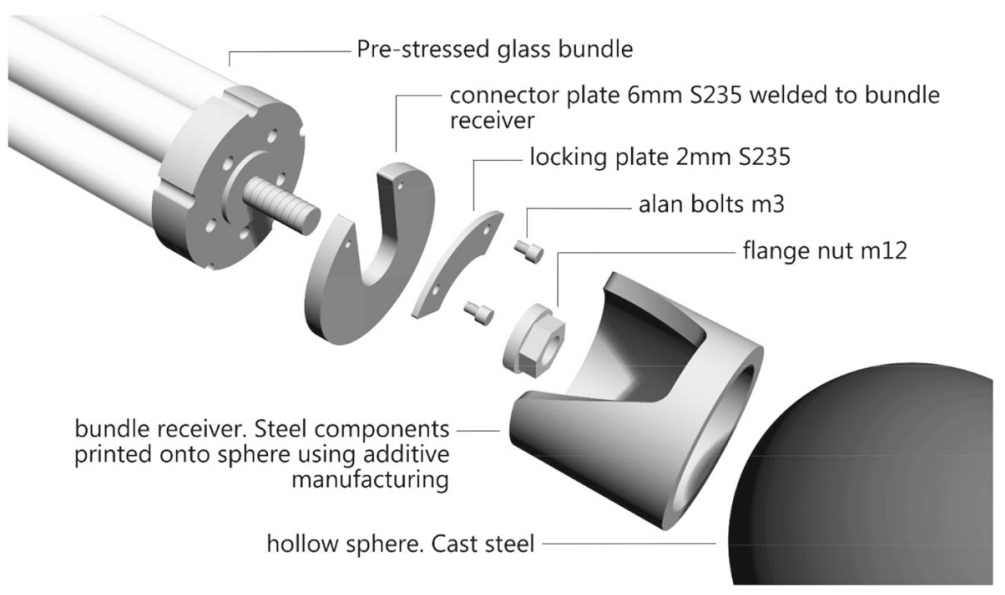




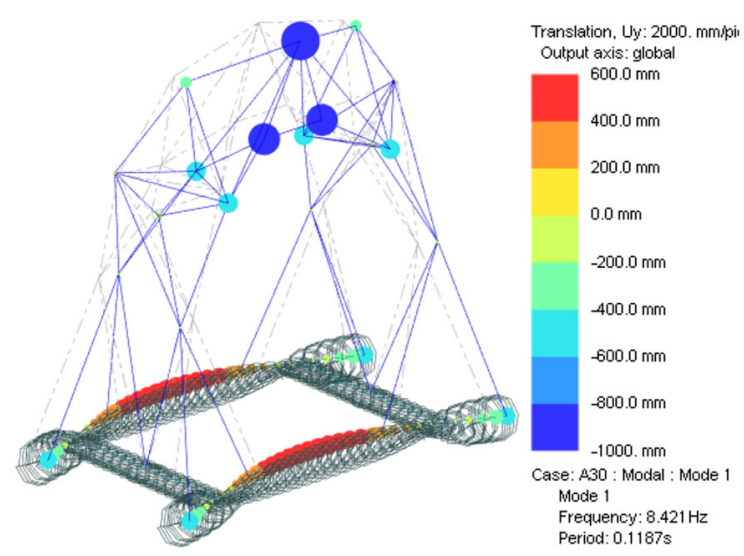

Fig. 29 Modal analysis showing first eigen mode

of a strategy for taking up tolerances in the connections. Due to shorter cooling times than required, some distortion of the geometry occurred reducing geometrical accuracy.

\section{Structural analysis of the swing}

\subsection{Static calculation}

Oasys GSA was used to verify the calculations of Karamba3D under critical angle loading. Also, to ensure that higher forces than induced by critical angle loading were not missed, all struts were checked for three additional loading scenarios: (1) the swing at a vertical angle (0 degrees) will result in the largest vertical force to the swing structure; (2) an angle of 45 degrees; and (3) although a perfect swing motion does not induce a horizontal force at the point of reversing the motion, a horizontal load with an angle of 90 degrees to the vertical. Also, loading in the transverse direction to the swing motion was checked.

The structure was then checked for displacements. Due to the stiff nature of a truss structure, the displacements were found to be below $2 \mathrm{~mm}$.

\subsection{Dynamic calculation}

To study the dynamic behavior of the structure, a modal analysis was carried out. The frequency of the first mode shapes, starting from $8.4 \mathrm{~Hz}$ (see Fig. 29), were found to be much higher than the frequency of the swing of $0.35 \mathrm{~Hz}$.

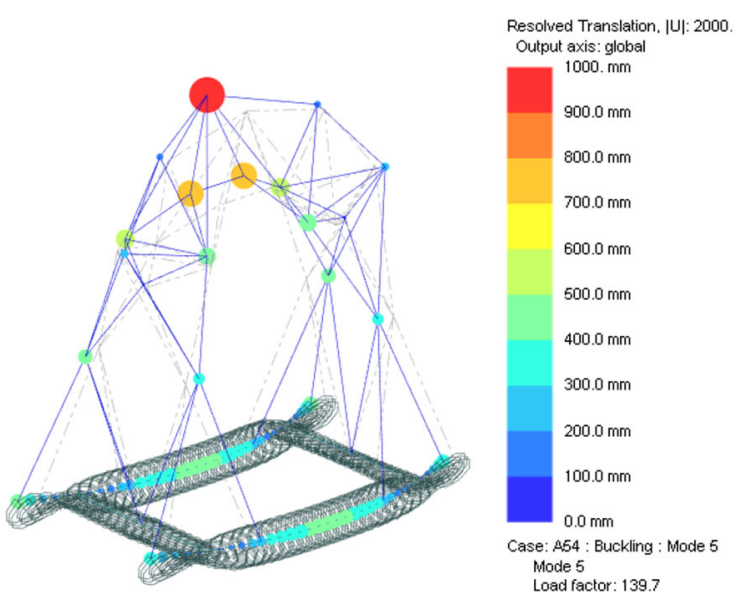

Fig. 30 Buckling analysis showing the first positive buckling load factor

\subsection{Global and local stability}

Because the swing is not mounted to the underlying structure (exhibition floor), the structure is not able to resist uplift. Therefore, the global stability of the structure was assessed on overturning moment due to the horizontal component of the swing motion. The mass of the structure was found to be large enough to compensate for overturning. Also, with a buckling analysis the global buckling load factor was determined to be 139.7, see Fig. 30.

\subsection{Structural verification of the nodes}

In the absence of design rules for additively manufactured steel, the stresses in the AM parts had to be limited to a level that satisfied the designers. Determining the acceptable level was challenging due to the unknown fatigue life properties of the material under dynamic loading. Preliminary research results at TU Delft (expected publication in 2020) show that the fatigue life of WAAM produced material is lower than the fatigue life expected for similar material produced in a conventional way. In comparison with the frequently used rule of thumb that the fatigue limit is half the ultimate tensile strength, a $10 \%$ limit of the tensile strength seemed to be justifiable and a safe assumption. The maximum tensile stresses were limited to 0.1 $* \mathrm{f}_{\mathrm{u}}=0.1 * 490=49 \mathrm{MPa}$ for the used material S355.

Via linear static analysis the stresses in the heaviest loaded node were determined, see Fig. 31. Based on 


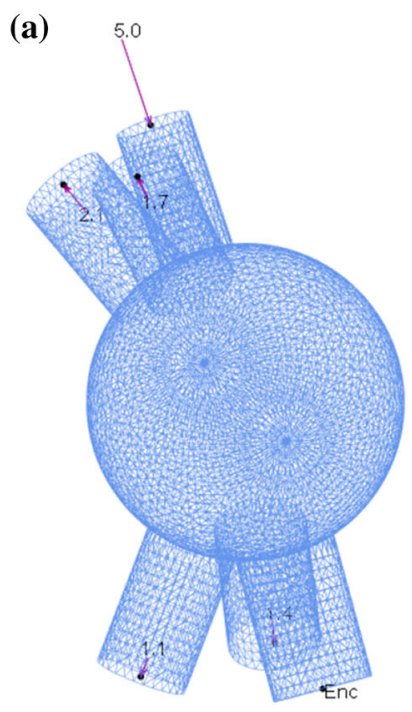

(b)

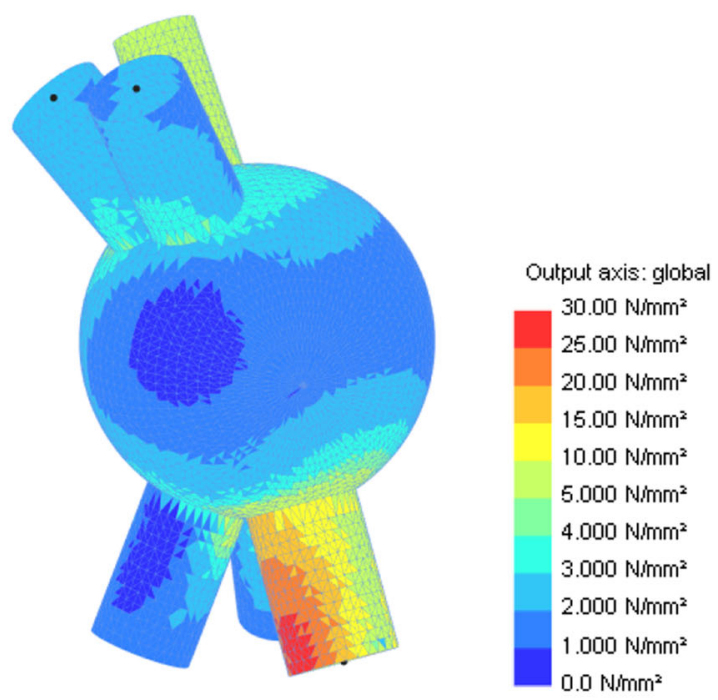

Fig. 31 a analytical model of the node with corresponding loads, printed structure $\mathrm{t}=6 \mathrm{~mm}$, cast sphere $\mathrm{d}=150 \mathrm{~mm}$ and $\mathrm{t}=12 \mathrm{~mm}$. b Von Mises stresses $[\mathrm{MPa}]$ in the node

the derived stresses the wall thickness for this node was determined. Maximum expected design load acting on the nodes was $5 \mathrm{kN}$. Stress concentrations of $30 \mathrm{MPa}$ were expected to occur. Average stresses in the printed material are expected to be between 10 and $20 \mathrm{MPa}$. Since the wall thickness of the cast sphere is larger than the printed wall thickness the stresses are lower, around $5 \mathrm{MPa}$.

Based on the outcome of the heaviest loaded node, the same wall thickness was used for all the nodes. The procedure could have been extended to minimize the wall thickness for each unique node, however due to time constraints the node with highest design loads was analyzed.

\section{Discussion and conclusions}

\subsection{Discussion}

The Glass Swing is the result of the ongoing experimental research of the Glass and Transparency Group of the Delft University of Technology. The structure has at the time of writing been assembled and dissembled 9 times for different events (see Fig. 32). One of the most time-consuming problems that was faced was torsion of the bundles. The dry-assembled bundles have very low to no capacity to resist torsion.
Torsional deformation of the bundle results in vulnerability to failure in bending. When the bundles are parallel (no torsion) a bending moment is taken up by tension in the central steel rod and compression in the glass rods. Via this mechanism considerable moments can be resisted.

Inaccuracy of the AM produced nodes contributed to difficulties when assembling the structure. For this project it was mainly due to the manually welded connector end plate to the printed node. This could be improved by including the connector plate in the print strategy or finding a strategy to correctly apply the connector plate manually. Moreover, it could be anticipated by implementing methods to include tolerances.

The applied printed material requires further research and development. The stresses in the printed parts had to be kept to an acceptable level because of the lack of design rules with respect to uncertainty in the material quality and also fatigue. Testing programs and experience could lead to the development of design rules for AM produced parts which will result in confidence and more efficient designs in terms of material usage.

The production setup consisting of a rotary table and a welding robot have been found to be beneficial to print non-planar geometry and to print on non-planar substrates. However, it results in challenging programming of the machine movement. Although interaction between AM produced material and the used substrate 
Fig. 32 The Glass Swing at the GlassTec in Dusseldorf

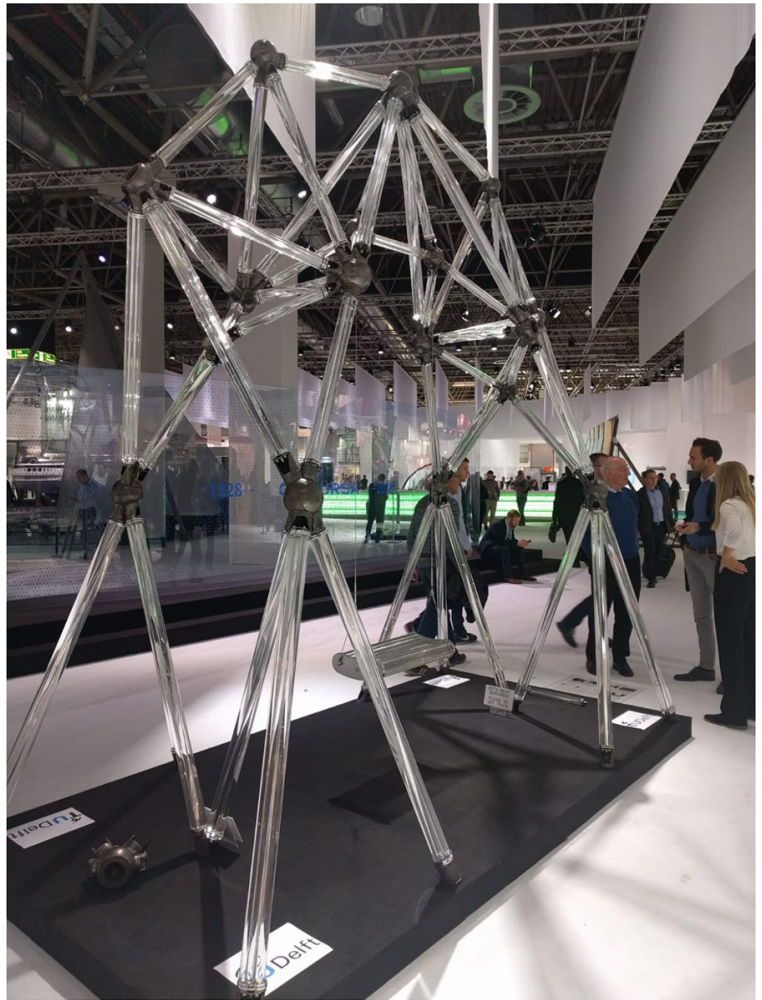

is unknown, it provides evidence that it could be applied in a wider range of applications: the design of partial structures with non-planar substrates or the repair of non-planar geometry.

The structure was designed and manufactured in a timespan that was tight, considering the number of innovations in the project. The design calculations accompanied with tests at the TU Delft have proven that the Glass Swing is a safe structure.

\subsection{Conclusions}

The Glass Swing is the first glass vector active structure successfully applying dry assembled glass bundles. The bundles are still experimental and require further development and testing before practical application. Most notably the problem of torsion requires attention.

The dry-assembled bundles are quickly and easily produced in various diameters and this makes them suitable for structural optimization.

Partially additively manufactured nodes by WAAM can be applied for spatial structures. It can potentially help to overcome difficulties with production by tradi- tional methods. Especially, when these nodes are geometrically complex, such as unique and tight angles.

It is possible to use non-planar objects as substrate for manufacturing by WAAM. With the nodes for the Glass Swing a rotary table and a complex printing strategy was successfully adopted.

The design intent was to create a glass structure that combines qualities of glass art and architectural glass. The end product shows what an intentional combination of the aesthetic and structural properties of glass can look like.

Acknowledgements The Duran glass rods were provided and cut to size free of charge by Schott; The 3D printed nodes were provided free of charge by RAMLAB; The cast steel spheres were provided free of charge by Octatube; The consumable wire for the manufacturing of the nodes was provided by Lincoln Electric Europe free of charge. TU Delft student Alex Kouwenhoven developed the initial concept; The work of Matthijs Visser, Tolga Özdemir, Kees Baardolf and Lourens Broeks was essential for a timely completion. CG would like to acknowledge funding from project number S16043 in the framework of the Partnership Program of the Materials innovation institute M2i (www.m2i.nl) and the Technology Foundation TTW (www.stw.nl), which is part of 
the Netherlands Organization for Scientific Research (www.nwo. nl).

\section{Compliance with ethical standards}

Conflict of interest statement On behalf of all authors, the corresponding author states that there is no conflict of interest.

Open Access This article is distributed under the terms of the Creative Commons Attribution 4.0 International License (http:// creativecommons.org/licenses/by/4.0/), which permits unrestricted use, distribution, and reproduction in any medium, provided you give appropriate credit to the original author(s) and the source, provide a link to the Creative Commons license, and indicate if changes were made.

\section{References}

Achenbach, J., Behling, S., Doenitz, D.D., Jung, H.: Verbundglasrohr als konstruktives element. In: Glasstechnology Live, Katalog zur Architektursonderausstellung, Düsseldorf, (2002)

Bos, F.P.: Hybrid glass-acrylic façade struts. In: Glass Performance Days 2007, pp. 222-226. GPD (2007)

Bos, F.P., Veer, F.A., Heidweiller, A.J.: Using plastics in the design of joints in transparent structures. In: Proceedings of the 2nd International Symposium on Architectural Applications of Glass (ISAAG), Munich (2006)

Chen, W.-F., Lui, E.: Handbook of Structural Engineering. CRC Press, Boca Raton (1999)

Conturax. / SCHOTT AG (2017). https://www.schott.com/ tubing.Mitterteich

Crolla, K., Williams, N., Muehlbauer, M., Burry, J.: Towards custom-optimized nodes applications in construction. In: 22nd International Conference of the Association for Computer-Aided Architectural Design Research in Asia (CAADRIA), Hong Kong (2017)

Doenitz, FD., Jung, H., Behling, S., Achenbach, J.: Laminated glass tubes as structural elements in building Industry. In: 8th International Conference on Automotive and Architectural Glass, Tampere (2003)

Galjaard, S., Hofman, S., Perry, N., Ren, S.: Optimizing structural building elements in metal by using additive manufacturing. In: Proceedings of the International Association of Shell and Spatial Structures (IASS), Amsterdam (2015)
Hartsuijker, C., Welleman, J.W.: Constructie Mechanica 3: Statisch Onbepaalde Constructies en Bezwijkanalyse. Academic Service, The Hague (2007)

Hestermann, U., Rongen, L.: Fassaden aus Glas. Springer, Wiesbaden (2015)

M2i, Aim2XL program started, 05 July 2018. https://www.m2i. n1/news/aim2xl-program-started (2018). Accessed 07 Dec 2018

MX3D, MX3D Bridge, MX3D. https://mx3d.com/projects/ bridge (2018). Accessed 07 Dec 2018

Nijsse, R.: Glass in Structures: Elements, Concepts, Designs. Birkhäuser, Delft (2003)

Oikonomopoulou, F., van den Broek, E., Bristogianni, T., Veer, F.A., Nijsse, R.: Design and experimental testing of the bundled glass column. In: Glass Structures and Engineering, pp. 183-200. 2(2), (2017)

Seifi, H., Xie, Y.M., O’Donnell, J., Williams, N.: Design and fabrication of structural connections using bi-directional evolutionary structural optimization and additive manufacturing. Appl. Mech. Mater. 846, 571-576 (2016)

Seifi, H., Rezaee Javan, A., Xu, S., Zhao, Y., Xie, Y.M.: Design optimization and additive manufacturing of nodes in gridshell structures. Eng. Struct. 160, 161-170 (2018)

Snijder, A., Nijsse, R., Louter, C.: The glass truss bridge. In: Heron, pp. 139-157. 63(1/2), (2018)

Van der Linden, L.: Innovative Joints for Gridshells, (2015)

WAAMpeller, the first certified 3D printed ship propeller, M2i, 03 April 2018. https://www.m2i.nl/news/ waampeller-the-first-certified-3d-printed-ship-propeller (2018). Accessed 07 Dec 2018

Xie, Y.M., Steven, G.P.: A simple evolutionary procedure for structural optimization. Comput. Struct. 49(5), 885-896 (1993)

Xie, Y.M., Steven, G.P.: Evolutionary structural optimization for dynamic problems. Comput. Struct. 58(6), 1067-1073 (1996)

Publisher's Note Springer Nature remains neutral with regard to jurisdictional claims in published maps and institutional affiliations. 